\title{
ARQUITETURA E DIMENSÃO DO SISTEMA RADICULAR DE SETE PORTA-ENXERTOS DE VIDEIRA NO NORTE DO ESTADO DO PARANÁ ${ }^{1}$
}

\author{
IVAN BORDIN², CARMEN SILVIA VIEIRA JANEIRO NEVES ${ }^{3}$, MATEUS CARVALHO BASÍLIO DE AZEVEDO², \\ WERNER GENTA ${ }^{4}$, THIAGO LUIZ RAGUGNETTI FURLANETO 5
}

\begin{abstract}
RESUMO - Foi estudada a estrutura do sistema radicular de sete porta-enxertos de videira das cultivares IAC 572, Kobber 5BB, Rupestris du Lot, IAC 313, IAC 766, Ripária do Traviú e 420 A, com cinco anos de idade. As raízes foram expostas por escavação e avaliadas pelo programa SIARCS 3.0. Foi utilizado um diagrama de arquitetura radicular, atribuindo-se notas à conformação do sistema radicular. O 'IAC 572' apresentou a maior extensão de raízes e o ' 420 A', a menor. Os porta-enxertos não apresentaram diferença quanto à arquitetura do sistema radicular. Os mais vigorosos apresentaram maior proporção de raízes enoveladas.
\end{abstract}

Termos para indexação: Vitis sp., escavação, comprimento de raízes.

\section{ARCHITECTURE AND EXTENSION OF ROOTS OF SEVEN GRAPEVINE ROOTSTOCKS IN NORTH OF PARANÁ STATE}

ABSTRACT - It was studied the structure of the root system of 5 year old IAC572, Kobber 5BB, Rupestris du Lot, IAC 313, IAC 766, 'Ripária do Traviú' and 420 A grapevine rootstocks. The roots were exposed using the excavation method and evaluated by the SIARCS 3.0 software. To evaluate the conformation of the rootskocks root system it was used an architecture diagram attributing scores. 'IAC 572' had the largest root system and ' 420 A' had the smallest. There were no statistical differences in scores atributed to the architeture of the root systems. The most vigorous had the highest distortion frequency.

Index Terms: Vitis sp., excavation method, root lenght.

O sucesso da produção de uvas de mesa depende da cultivar de porta-enxerto utilizada devido às características que cada uma delas apresenta quanto à adaptação às condições do solo, clima, facilidade de enraizamento, vigor, longevidade, resistência a pragas e capacidade de absorver nutrientes (Kishino \& Mashima, 1980). Para isso é essencial que uma planta tenha uma boa arquitetura radicular que permita o melhor estabelecimento e exploração do solo e absorção de água e nutrientes, resistindo a possíveis deficiências hídricas (Reis et al., 1996).

O conhecimento sobre a quantidade e distribuição das raízes é importante para a produção agrícola por fornecer informações úteis às práticas de manejo, como espaçamento de plantio, culturas intercalares, manejo do solo, irrigação e, principalmente, a otimização da distribuição de adubos (Neves et al., 2001). Segundo Fregoni (1980), a nutrição das videiras, além da marcada influência na produção, atua ainda na maturação, formato, firmeza da polpa, cor, tamanho, uniformidade, concentração de açúcares e acidez das bagas.

A propagação dos porta-enxertos por estaquia permite ao sistema radicular da videira apresentar-se fasciculado, com a particularidade de emitir raízes a cada gema da estaca, distribuindo-se em uma ou mais camadas, influenciando na formação da arquitetura radicular (Redondo, 1970). Devido à escassez de informações sobre a arquitetura do sistema radicular de videiras, o presente trabalho objetivou avaliar a conformação das raízes de sete porta-enxertos, utilizando o método da escavação, nas condições do Norte do Paraná.

$\mathrm{O}$ experimento foi realizado na primeira quinzena de agosto de 2002 no Município de Marialva - PR, localizado a $23^{\circ} 27^{\prime} \mathrm{S}, 51^{\circ} 47^{\prime} \mathrm{W}$, altitude de $600 \mathrm{~m}$, em um Latossolo Vermelho distroférrico (LVdf) de textura muito argilosa.

Foram avaliadas sete variedades de porta-enxertos (IAC 572, Kobber 5BB, Rupestris du Lot, IAC 313, IAC 766, Ripária do Traviú e $420 \mathrm{~A}$ ), que estavam plantadas no espaçamento de $4 \times 4 \mathrm{~m}$ há cinco anos, sendo avaliadas quatro plantas por variedade. As mudas foram propagadas por estaquia em sacos plásticos de $2 \mathrm{~L}$ e plantadas em covas abertas com broca mecânica de diâmetro de 20', com adição de 20 $\mathrm{L}$ de esterco de curral suplementado com $0,6 \mathrm{~L}$ de adubo químico da formulação 0-20-20. O manejo das plantas foi limitado a roçadas. As plantas não receberam irrigação, adubação ou enxertia depois de transferidas para o campo.

Os porta-enxertos foram expostos por escavação (Böhm, 1979), delimitando-se um círculo, ao redor de cada planta, de 1,2 $\mathrm{m}$ de raio. O solo foi cuidadosamente retirado partindo-se da periferia para o centro da área assim delimitada, a fim de evitar-se o corte de raízes próximas ao tronco, até a profundidade de $60 \mathrm{~cm}$. Os sistemas radiculares foram levados a um galpão e suspensos e fotografados, nas posições lateral e superior. As fotografias foram avaliadas pelo Sistema Integrado de Análise de Raízes e Cobertura do Solo (SIARCS 3.0) (Crestana et al., 1994) e as variáveis comprimento e área avaliadas. Os dados obtidos foram submetidos à análise de variância e as médias ao teste Tukey, com $5 \%$ de probabilidade.

Para avaliar a arquitetura dos sistemas radiculares foi utilizado um diagrama de notas, onde a nota zero foi atribuída aos sistemas radiculares com melhor conformação e a nota 10 , às piores conformações (Mason, 1985). A avaliação da possível influência dos recipientes plásticos sobre as deformações das raízes foi determinada através da freqüência de raízes enoveladas, atribuindo-se nota zero para a ausência de raízes em espiral próximas ao tronco e aumentando-se as notas à medida que o número de raízes enoveladas aumentava. A nota 10 foi atribuída quando todas as raízes apresentavam-se espiraladas. As notas foram submetidas ao teste de Kruskal-Wallis.

Os porta-enxertos 'IAC 572' e 'Rupestris du Lot' tiveram a área radicular, nas imagens laterais, superiores ao ' 420 A', igualando-se aos demais (Tabela 1). Para a área referente às imagens superiores, o 'IAC 572' superou o ' 420 A', não se diferenciando dos demais.

Quanto ao comprimento das raízes referentes às imagens laterais (Tabela 1), observou-se também que o porta-enxerto 'IAC 572' foi superior o 'Kobber 5BB' e ' 420 A', não se diferenciando das variedades Rupestris du Lot, IAC 313, IAC 766 e Ripária do Traviú. Para as imagens superiores, o comprimento das raízes dos porta-enxertos 'IAC 572', 'Rupestris du Lot', 'IAC 313' e 'Ripária do Traviú' não se diferenciaram de 'IAC 766' e 'Kobber 5BB', superando apenas o ‘420 A'. O desempenho apresentado pelo porta-enxerto ' 420 A' pode ser explicado pelo seu vigor médio e sua dificuldade de desenvolver-se em

\footnotetext{
(Trabalho 052/2003). Recebido: 31/02/2003. Aceito para publicação: 7/11/2003.

${ }^{2}$ Mestrando em Agronomia. UEL, C.P. 6001, CEP 86051-990, Londrina, PR. Bolsista CAPES

${ }^{3}$ Enga.Agr $^{\text {a. }}$, Prof ${ }^{a}$. Dra., Dep. de Agronomia, UEL, Londrina, PR. E-mail: csvjneve@uel.br

${ }^{4}$ Eng $^{\mathrm{O}}$ Agr ${ }^{\mathrm{o}}$,Associação Norte Paranaense de Estudos em Fruticultura-ANPEF, Marialva, PR

${ }^{5}$ Graduando em Agronomia, UEL, Londrina, PR. Bolsista PIBIC/CNPq
} 
TABELA 1 - Área e comprimento dos sistemas radiculares de portaenxertos de videira, em imagens laterais e superiores. Marialva-PR, 2002.

\begin{tabular}{lcccccccccc}
\hline & \multicolumn{3}{c}{ Área $\left(\mathrm{cm}^{2}\right)$} & & \multicolumn{4}{c}{ Comprimento $(\mathrm{cm})$} \\
\hline Porta-enxerto & \multicolumn{3}{c}{ Lateral } & \multicolumn{3}{c}{ Superior } & & Lateral & \multicolumn{3}{c}{ Superior } \\
\hline IAC 572 & 1609 & $* \mathrm{a}$ & 1726 & $\mathrm{a}$ & & 3994 & $\mathrm{a}$ & 3410 & $\mathrm{a}$ \\
Kobber 5BB & 1540 & $\mathrm{ab}$ & 1341 & $\mathrm{ab}$ & & 2455 & $\mathrm{bc}$ & 2490 & $\mathrm{ab}$ \\
Rup. du Lot & 1324 & $\mathrm{a}$ & 1392 & $\mathrm{ab}$ & & 2987 & $\mathrm{ab}$ & 2896 & $\mathrm{a}$ \\
IAC 313 & 1281 & $\mathrm{ab}$ & 1346 & $\mathrm{ab}$ & & 2791 & $\mathrm{ab}$ & 3064 & $\mathrm{a}$ \\
IAC 766 & 1260 & $\mathrm{ab}$ & 1230 & $\mathrm{ab}$ & & 3080 & $\mathrm{ab}$ & 2460 & $\mathrm{ab}$ \\
Rip. do & & & & & & & & \\
Traviún & 1193 & $\mathrm{ab}$ & 1351 & $\mathrm{ab}$ & & 2896 & $\mathrm{ab}$ & 2942 & $\mathrm{a}$ \\
420 A & 604 & $\mathrm{~b}$ & 967 & $\mathrm{~b}$ & & 1270 & $\mathrm{c}$ & 1478 & $\mathrm{~b}$ \\
\hline CV \% & \multicolumn{2}{c}{25} & 24 & & 20 & & 19 & \\
\hline
\end{tabular}

*Médias seguidas da mesma letra, na coluna, não diferem entre si pelo teste Tukey a 5\% de significância.

solos ácidos (Terra et al., 1993). A maior extensão apresentada pelos sistemas radiculares das plantas de 'IAC 572' e 'Rupestris du Lot' pode ser muito útil quando sob condições de falta de água no solo, por permitir a estas plantas a exploração de um maior volume do solo, reduzindo o estresse hídrico, caracterizado pelo fechamento dos estômatos, e conseqüente diminuição da difusão de $\mathrm{CO}_{2}$ para o mesófilo foliar. Esse último processo acaba por causar a queda na intensidade de fotossíntese, ocasionando a redução no tamanho das bagas, atraso no amadurecimento, afetando a coloração e provocando queimaduras pelo sol (Souza et al., 2001).

Segundo Iannini (1984), os porta-enxertos apresentam grande variação no vigor em conseqüência das diferentes exigências nutricionais e capacidade de absorção de água e nutrientes, devido a uma seletividade radicular na absorção de íons da solução do solo. Este fato foi observado por Alburquerque \& Dechen (2000), que em sistema de hidroponia, confirmaram o maior vigor do porta-enxerto 'IAC 572', quanto à capacidade de acumular nutrientes, do que as variedades IAC 313, IAC 766, Dog Ridge, Salt Creek e Harmony na extração de N, P, K e Ca e igual ao 'IAC 313' na extração de Mg, resultando maior exigência nutricional e capacidade de produção de biomassa.

Quanto às médias das notas atribuídas às imagens laterais dos porta-enxertos (Tabela 2), observa-se que ocorreram diferenças não significativas entre eles, o que indica que, apesar das diferenças na extensão das raízes, a arquitetura radicular foi semelhante em todos os porta-enxertos. As médias das notas da arquitetura nas imagens

TABELA 2 - Notas do diagrama de arquitetura dos sistemas radiculares de porta-enxertos de videira, em imagens laterais e superiores e notas de freqüência de raízes enoveladas. Marialva-PR, 2002.

\begin{tabular}{lcccccc}
\hline \multirow{2}{*}{ Porta-enxerto } & \multicolumn{3}{c}{ Notas de arquitetura } & \multicolumn{2}{c}{$\begin{array}{c}\text { Freqüência de } \\
\text { raínes enoveladas }\end{array}$} \\
\cline { 2 - 5 } IAC 572 & 9,5 & $\mathrm{a}^{*}$ & 3,0 & $\mathrm{a}$ & 9,0 & $\mathrm{a}$ \\
Kobber 5BB & 9,0 & $\mathrm{a}$ & 2,5 & $\mathrm{a}$ & 1,0 & $\mathrm{~b}$ \\
Rup. du Lot & 9,5 & $\mathrm{a}$ & 4,0 & $\mathrm{a}$ & 2,0 & $\mathrm{ab}$ \\
IAC 313 & 9,0 & $\mathrm{a}$ & 1,0 & $\mathrm{a}$ & 3,0 & $\mathrm{ab}$ \\
IAC 766 & 8,0 & $\mathrm{a}$ & 5,0 & $\mathrm{a}$ & 2,0 & $\mathrm{ab}$ \\
Rip. do Traviún & 8,5 & $\mathrm{a}$ & 1,0 & $\mathrm{a}$ & 5,5 & $\mathrm{ab}$ \\
420 A & 8,0 & $\mathrm{a}$ & 1,5 & $\mathrm{a}$ & 1,0 & $\mathrm{~b}$ \\
\hline
\end{tabular}

*Médias seguidas da mesma letra, na coluna, não diferem entre si pelo teste Kruskal-Wallis.

superiores (Tabela 2) também apresentaram diferenças que não foram significativas entre os tratamentos.

Em relação à freqüência de raízes enoveladas, o porta-enxerto 'IAC 572' foi superior ao 'Kober 5BB' e ao '420-A', não se diferenciando dos demais (Tabela 2). Estes resultados condizem com as maiores extensões de raízes e, portanto, maior vigor apresentados pelo 'IAC 572' (Tabela 2), demonstrando um enovelamento próximo ao tronco devido à limitação oferecida pelos recipientes ao desenvolvimento radicular, principalmente para as cultivares mais vigorosas. Este fato é importante a ser considerado no planejamento e plantio dos pomares, sendo que os porta-enxertos mais vigorosos devem ficar menos tempo nos recipientes antes do plantio no local definitivo. Dentre os vários problemas que podem ser ocasionados pelas partes deformadas do sistema radicular, destacam-se a interferência na partição de hidratos de carbono, produção e transporte de reguladores de crescimento e absorção de água e nutrientes (Hay \& Woods, 1978), que tendem a se intensificar à medida que aumenta a deficiência hídrica (Reis \& Hall, 1987).

Pode-se concluir que o porta-enxerto 'IAC 572' apresenta o maior comprimento de raízes, enquanto que o '420-A' apresenta o menor. Os porta-enxertos avaliados não apresentam diferenças no que diz respeito à arquitetura do sistema radicular. Os porta-enxertos mais vigorosos apresentam maior proporção de raízes enoveladas.

\section{REFERÊNCIAS BIBLIOGRÁFICAS}

ALBUQUERQUE, T. C. S.; DECHEN, A. R. Absorção de macronutrientes por porta-enxertos e cultivares de videira em hidroponia. Scientia Agricola, Piracicaba, v. 57, n. 1, p. 135-139, 2000.

BÖHM, W. Methods of studyng root systems. Berlim: Springer-Verlag, 1979. 188p.

CRESTANA, A.; GUIMARÃES, M. F.; JORGE, L. A. C.; RALISCH, R.; TOZZI, C. L., TORRES, A.; VAZ, C. M. P. Avaliação da distribuição de raízes no solo auxiliada por processamento de imagens. Revista Brasileira de Ciência do Solo, Viçosa, v. 18, p. 365-371, 1994.

FREGONI, M. Nutrizione e fertilizzazione della vite. Bolonha: Edagricole, 1980.418p.

HAY, R. L.; WOODS, F. W. Carbohydrate relationships in root system of planted loblolly pine seedlings. In: SYMPOSIUM OF THE ROOT FORM PLANTED TREES, 1., 1978, Victoria. Proceedings... Victoria, 1979, p. 73-84.

IANNINI, B. Importanza e funzioni del portinnesto nella viticoltura moderna. Revista di Viticoltura e di Enologia, n. 7-8, p. 394-419, 1984.

KISHINO, A. Y.; MASHIMA, M. Uva. In: IAPAR, Manual Agropecuário para o Paraná. Londrina: IAPAR, 1980, p. 139-177.

MASON, E. G. Causes of juvenile instability of Pinus radiata on ripped and unipped taupo pumice soil. New Zealand Journa of Forestry of Science, Rotora, v. 15. n. 3, p.263-280, 1985.

NEVES, C. S. V. J.; BORGES, A. V.; KANAI, H. T.; PRETE, C. E. C.; CARPENTIERI-PÍPOPLO, V. Distribuição do sistema radicular da aceroleira. Revista Brasileira de Fruticultura, Jaboticabal, v. 23, n. 1, p. 112-115, 2001.

REDONDO. L. R. Viticultura enologia y fruticultura. Barcelona:Aedos, 1970.218p.

REIS, G. G; HALL, A. E. Relações hídricas e atividade do sistema radicular em Eucalyptus camaldulensis Dehn em condições de campo. Revista Árvore, Viçosa, v. 11, n. 1, p. 43-55, 1987.

REIS, G. G.; REIS, M. G. F.; RODRIGUES, F. L.; BERNARDO, A. L.; GARCIA, N. C. P. Efeito da poda de raízes de mudas de eucalipto produzidas em tubetes sobre a arquitetura do sistema radicular e o crescimento no campo. Revista Árvore, Viçosa, v. 2, n. 1, p. 137-145, 1996.

SOUZA, C. R.; SOARES, A. M.; REGINA, M. A. Trocas gasosas de mudas de videira, obtidas por dois porta-enxertos, submetidas à deficiência hídrica. Pesquisa Agropecuária Brasileira, Brasília, v. 36, n.10, p. 1221-1230, 2001.

TERRA, M. M.; PIRES, E. J. P.; NOGUEIRA, N. A. M. Tecnologia para a produção de uva Itália na região noroeste do Estado de São Paulo.Campinas: CATI, 1993. 51p. (Documento Técnico, 97). 